\title{
Associações criativas entre quadrinhos e pintura
}

\section{Creativity associations between comics and painting}

\author{
Marcus Vinicius de Paula \\ Professor da Escola de Belas Artes (EBA), Universidade Federal do Rio de Janeiro \\ (UFRJ) \\ depaulamarcusvinicius@gmail.com \\ orcid.org/0000-0003-4870-9249
}

\section{Lucas Almeida de Melo}

Mestrando no Programa de Pós-graduação em Design da Escola de Belas Artes (PPGD-EBA), Universidade Federal do Rio de Janeiro (UFRJ)

lmelo496@gmail.com

orcid.org/0000-0001-8518-8839

\section{Matheus Nascimento da Silva}

Graduando em Educação Artística com Habilitação em Artes Plásticas pela Escola de Belas Artes (EBA),Universidade Federal do Rio de Janeiro (UFRJ)

jadejishi@ufrj.br

orcid.org/0000-0002-8005-3000

Resumo. O artigo é resultado do diálogo entre dois trabalhos de iniciação científica que fazem parte do projeto de pesquisa "Arte e Comunicação Visual: A linguagem dos quadrinhos e a questão da narrativa na pintura acadêmica", orientado pelo professor Marcus Vinícius de Paula. Vamos analisar e comparar as relações entre duas experiências que associam a história da pintura à linguagem dos quadrinhos. Em primeiro lugar apresentaremos o álbum "AuFil de l'Art" de Gradimir e Ivana Smudja, e, em seguida, a "História em Quadrões" por Mauricio de Sousa. Por fim, procuraremos demonstrar suas semelhanças e particularidades criativas.

Palavras-chave: Criatividade; História em Quadrinhos; Pintura Acadêmica; História em Quadrões; AuFil de l'Art. 
Abstract. This article is the result of a dialogue between two scientific initiation works that are part of the research project "Arte e Comunicação Visual: Uma linguagem dos quadrinhos e uma questão da narrative na pintura acadêmica" supervised by professor Marcus Vinicius de Paula. We will analyze and compare how relation ships between two experiences that associate a history of painting with the language of comics. We introduce the album "Au Fil de I'Art" by Gradimir and Ivana Smudja, and then a "História em Quadrões " by Mauricio de Sousa, triyng to demonstrate their similarities and creative peculiarities.

Keywords: Creativity; Comics; Academic Painting; História em Quadrões; Au Fil de l'Art.

Recebido: 01/10/2017 Aceito: 27/10/10 Publicado: 07/11/2017

\section{Introdução}

Pretendemos mostrar duas experiências criativas que lidam com o diálogo entre as linguagens dos quadrinhos e da pintura. Ambos os trabalhos apresentados lidam com essa questão, mas de maneiras bem distintas. O primeiro apresenta o álbum "AuFil de l'Art", um quadrinho francês, que narra, com muito humor, episódios da história da pintura. O segundo, por sua vez, lida com as publicações e exposições denominadas História em Quadrões, do artista brasileiro Mauricio de Sousa, que transporta os icônicos personagens da Turma da Mônica para telas inspiradas em pinturas célebres da história da arte.

\section{Metodologia}

A raiz metodológica utilizada nesta pesquisa baseia-se na noção de iconologia. Esse método de abordagem da imagem foi instituído por Aby Warburg e Erwin Panofsky na primeira metade do século XX. Mais recentemente William Mitchell estabeleceu um novo marco e reformulou esse conceito por meio dos livros "Iconology, image, text, ideology" (MITCHELL, 1987) e Picture Theory (MITCHELL, 1995) criando o que ele denominou como iconologia crítica. O método iconológico que utilizaremos aqui, apesar de partir das diretrizes estabelecidas por Mitchell, será mais comparativo. Os fundamentos dessa iconologia comparativa (ou do que denominaremos também como intericonicidade) estão definidos pelo orientador desta pesquisa no artigo A Fratura Iconológica (DEPAULA, 2012).

A análise se apoiou em três fundamentos bibliográficos: em primeiro lugar estão, como já mencionamos, as diretrizes iconológicas; em seguida utilizamos também autores 
especializados na análise da linguagem em quadrinhos, como Scott McCloud, Will Eisner, Thierry Groensteen e Umberto Eco. Para analises das pinturas, usamos os livros da editora Taschen sobre a vida e obra de artistas renomados, vários deles citados no quadrinho europeu "AuFil de l'Art" e no material brasileiro "História em Quadrões".

\section{AuFil de l'Art}

“AuFil de l'Art” foi produzido pela editora francesa Decourt, em 2012 (ainda não existe tradução para português) e é composto por dois volumes com lombada quadrada, capa dura e com aproximadamente duzentas páginas cada um. Narra, através da linguagem dos quadrinhos, pequenas passagens fictícias da vida de grandes mestres da história da arte europeia.

A narrativa é costurada por meio das aventuras da jovem Luna e seu gato falante Vincent, uma possível homenagem a Vicent van Gogh e/ou Leonardo da Vinci. Tudo começa quando esses personagens tropeçaram em uma linha vermelha e caem em um buraco que os leva às cavernas de Lascaux, no sudoeste da França. Essa linha vermelha é um importante meio gráfico que aparece e desaparece em diversas cenas.

A cada mudança de época e de pintores, nos deparamos com duas páginas, em tom de sépia, destinadas a uma breve biografia do artista. Nessas páginas, a linha vermelha se destaca e constrói um fio que perpassa todo o álbum e estimula as conexões entre os artistas.

A seriedade do discurso teórico e crítico da história da arte é substituída por uma narrativa brincalhona e descontraída, típica da linguagem dos quadrinhos. Questões complexas relativas à visão monocular de Leonardo às contorções maneiristas de Michelangelo são tratadas com o humor tópico da piada.

\section{História em Quadrões}

A ideia do livro "História em Quadrões" surgiu da necessidade de expor trabalhos que o autor, Mauricio de Sousa, realizou com a intenção de "incentivar a criatividade e divulgar a arte de um jeito divertido" (SOUSA, 2001, p. 9). Essa edição contou com 47 obras, incluindo uma escultura em isopor com revestimento em resina dentre as telas em tinta acrílica e foi publicada no ano de 2001 junto da exposição de mesmo nome.

Segundo Jacqueline Mouradin, curadora da exposição, "História em Quadrões" seguiu o seguinte itinerário desde o lançamento, conquistando quase um milhão de visitantes e dois prêmios no HQ Mix (Categoria de Melhor Exposição do Ano e Categoria Valorização das Histórias em Quadrinhos):

2001 - Pinacoteca do Estado de São Paulo

2002 - Museu Nacional de Belas Artes - Rio de Janeiro

2002 - Conjunto Cultural da Caixa - Salvador 
2002 - Museu Metropolitano de Arte - Curitiba

2003 - Conjunto Cultural da Caixa - Brasília

2004 - Palácio do Planalto - Brasília

2004 - Palácio das Artes - Belo Horizonte

2004 - Museu de Arte de Goiânia - Goiânia

2004 - Instituto Ricardo Brennand - Recife

Junto de uma segunda edição, publicada em 2010 com 45 obras diferentes sendo 14 delas esculturas, em 2014 as obras foram para a Coreia do Sul, tendo sido até o presente momento sua $13^{\text {a }}$ exposição no IksanArt Center Museum (27 de maio a 20 de agosto de 2017).

\section{A Criatividade em Aul Fil de L'Art e História em Quadrões}

No capítulo referente a Leonardo da Vinci utiliza a "Última Ceia" para explorar outro modo de representação, típico do Renascimento: “A perspectiva da Renascença é do tipo monocular uma vez que todas as linhas convergem para um só ponto" (SMUDJA, 2011, p.12). Neste famoso afresco, o espaço foi "construído de acordo com as regras de perspectiva central. As linhas de perspectiva encontram-se no olho direito de cristo, o que por si só enfatiza a sua posição central tanto na posição atual como na da representação" (ZÖLLNER, 2000, p.50).

Esse olhar renascentista pode ser também associado à contemplação prolongada e ao processo de reprodução calmo e vagaroso que atribuem a Leonardo. Em oposição a essa tranquilidade, Ivana e Gradimir Smudja colocam Luna e seu gato observando o artista num momento de grande agitação, pois não pode terminar a Última Ceia porque precisam recuperar os doze modelos que representam os apóstolos, que se encontram embriagados numa taberna. Porém, a anedota jocosa inventada por Smudja acaba por remeter ao processo artístico, na medida em que Leonardo procurou exaustivamente por modelos específicos para representar cada apóstolo. Frank Zöllner diz que: "Leonardo não poupou esforços para conseguir uma variedade de gestos e expressões faciais fortes que pudesse usar cada um dos discípulos: procurou mesmo modelos apropriados para as mãos" (ZÖLLNER, 2006, p.54).

Já no capítulo referente a Michelangelo, o artista se viu forçado a aceitar o convite do Papa Júlio II para decorar com afrescos a abóboda da Capela Sistina. Em "AuFil de L'Art”, Michelangelo está justamente envolvido com esse problema. Ele orgulhava-se de ser escultor e desprezava os pintores. Questionado por Luna, o casal Smudja usa de maneira inovadora o recurso do balão de fala para apresentar a solução compositiva (Figura 1). Estabelece uma conexão entre a linguagem da pintura e os quadrinhos, na medida em que a estrutura narrativa do teto é composta pelo emparelhamento de quadros. A esse respeito, Will Eisner comenta que o traçado do requadro é criado de 
acordo com a ação dada pelas exigências da narrativa e pelas dimensões da fala. (EISNER, 2001, p.51)

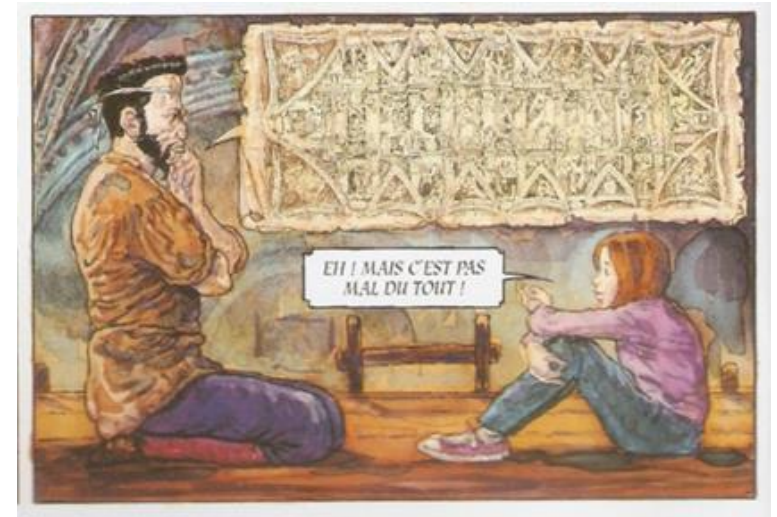

\section{Figura 1. "Ei! Mas não está mal de maneira alguma!"}

Fonte: SMUDJA, Ivana, SMUDJA, Gradimir. Au Fil de l'Art, volume 1.

Paris: Delcourt, 2012.

Mauricio de Sousa fez uso de seus personagens em releituras dos mais famosos quadros do mundo querendo que as crianças aprendessem mais sobre a história da arte e os autores das obras originais, para isso, junto das paródias estavam cópias dos originais.

Em A Criação do Cebolinha (Figura 2), assim como na pintura de Michelangelo "A Criação de Adão" Mauricio brinca com a temática da criação-criador retratando a si mesmo como criador e um de seus personagens como a criatura da criação. Algo importante a ser apontado é que no estudo do desenho antes de passar para a tela (Figura 3), Mauricio havia rascunhado o personagem Franjinha juntos dos outros próximos a si, entretanto ele foi retirado como é possível ver na arte finalizada. Para compreender o que aconteceu, deve-se entender primeiro que na parte direita do quadro, junto do autor, os personagens retratados como os anjos do Senhor ainda não existiam no mesmo plano que Cebolinha, naquele momento. Ou seja, eles estavam no plano das ideias, enquanto o Franjinha já existia com seu cachorro Bidu, sendo ambos os primeiros personagens criados. Logo, na criação do Cebolinha, Franjinha não poderia estar no plano das ideias. Cebolinha ainda traz consigo outro aspecto importante que o torna o personagem perfeito para estar no lugar de Adão (primeiro homem de Deus), sendo o personagem do quadrinista o primeiro principal da Turma da Mônica a ser criado.

Apesar da intenção meramente didática e conservadora de Mauricio de Sousa, a obra consegue superar esse propósito inicial e desperta potencial crítico, na medida em que o modelo iconográfico oriundo da austeridade acadêmica acaba sendo exposto ao riso. 


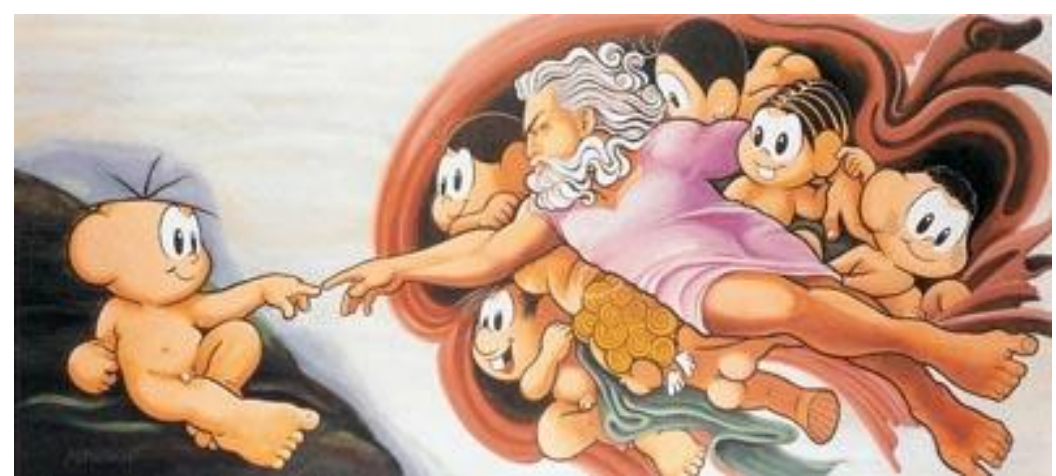

Figura 2. A Criação do Cebolinha

Fonte: SOUSA, Mauricio de. História em Quadrões - Pinturas de Mauricio de Sousa. São Paulo: Ed. Globo, 2001.

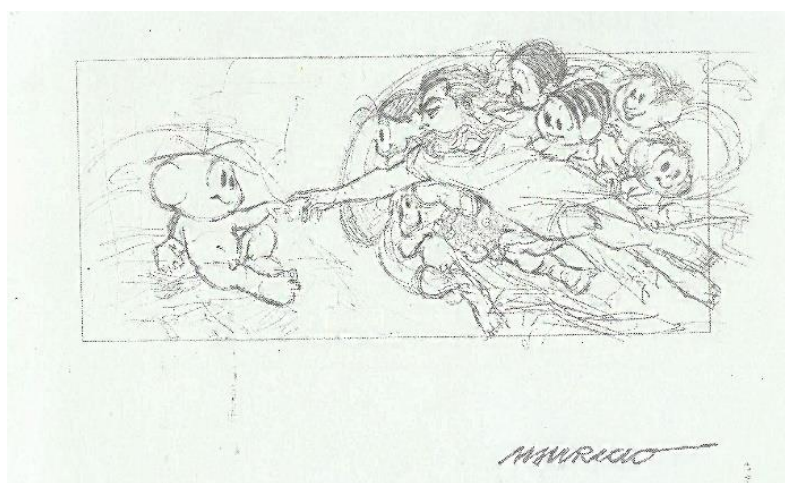

Figura 3. Rascunho de A Criação do Cebolinha

Fonte: SOUSA, Mauricio de. História em Quadrões - Pinturas de Mauricio de Sousa. São Paulo: Ed. Globo, 2001.

\section{Conclusões}

Comparando as duas experiências, tanto "AuFil de l'Art” quanto História em Quadrões estabelecem de modo criativo e divertido num diálogo entre quadrinhos e pintura. Podemos verificar inicialmente que "AuFil de l'Art" é um álbum em quadrinhos que tem como temática a história da pintura. Já na História em Quadrões, por sua vez resulta da produção de telas emolduradas que foram expostas em museus (de acordo com os códigos institucionais da pintura acadêmica). História em Quadrões gerou também dois livros que seguem o modelo dos catálogos de exposição de arte. Portanto, poderíamos a princípio deduzir, então, que enquanto "AuFil de l'Art" é uma experiência dos quadrinhos que remete à pintura, "História em Quadrões" é uma experiência da pintura que remete aos quadrinhos.

Talvez a resposta não seja tão simples assim, pois a linguagem da pintura não é apenas um pano de fundo temático para "AuFil de l'Art" e os personagens de Mauricio de Sousa não são apenas uma mera referência iconográfica para "História em Quadrões".

Vamos utilizar como estudo de caso para concluir esse trabalho o modo como cada uma destas experiências associou a pintura de Michelangelo à linguagem dos quadrinhos: 
Tanto "AuFil de l'Art" quanto "História em Quadrões" brincam com as diferentes estratégias figurativas difundidas pela história da pintura e pelos quadrinhos, entretanto Mauricio de Sousa estabelece as relações na aproximação de quadrinhos em pintura já em "AuFil de l'Art" a pintura que é transformada em quadrinhos. Além disso, o recurso transmidiático em "AuFil de l'Art", no qual o projeto da Capela Sistina é exposto dentro de um balão de fala, entrelaça as linguagens dos quadrinhos e da pintura induzindo reflexões gráficas no eleitor. Não é preciso utilizar uma obra em quadrinhos feita sobre a história da pintura para tratar da relação entre essas duas mídias. Isso porque é possível encontrar essa interseção em diversos quadrinhos onde essa relação não é evidente. Isso significa que se pode utilizar quadrinhos comerciais para o ensino de história da pintura como no exemplo encontrado. Assim, é interessante perceber que tanto Ivana e Gradimir Smudja quanto Mauricio de Sousa produzem uma "intericonicidade" entre as duas linguagens, porém criadas para diferentes tipos de reflexões entre as associações criativas entre quadrinhos e pintura.

\section{Referências}

DEPAULA, Marcus Vinicius. A Fratura Iconológica. In: Revista Poiésis 20, 2012.

A Pintura Histórica Degenerada: fundamentos da intericonicidade crítica da obra de arte. Rio de Janeiro: UERJ. Revista Concinnitas ano 17, vol. 1, n. 28 (p. 298 324), 2016.

ECO, Umberto. Apocalípticos e Integrados. São Paulo: Perspectiva, 1993.

EISNER, Will. Quadrinhos e arte sequencial. São Paulo: Ed. Martins Fontes, 2001.

GASCA, Luís. MENSURO, Asier. La pintura enelcómic. Madrid: Editiones Cátedra, 2014.

GROENSTEEN, Thierry. O Sistema dos Quadrinhos. Nova Iguaçu: Ed. Marsupial, 2015.

Mc CLOUD, Scott. Desvendando os quadrinhos. São Paulo: M. Books do Brasil Editora, 2004.

MITCHELL, W.J.T. Iconology, image, text, ideology. Chicago: The Universityof Chicago Press, 1987.

Picture Theory. Chicago: The Universityof Chicago Press, 1995.

MOZDZENSKI, L.; VAZ, A.; SILVA, M. C. H. Da obra-prima ao pastiche: multimodalidade e intericonicidade nos "Quadrões" de Mauricio de Sousa. 1. ed. Anais 
Eletrônicos. Recife: Universidade Federal de Pernambuco, 2008.Disponível em http://www.ufpe.br/nehte/simposio2008/anais/Leonardo-Mozdzenski-e-Ana-Vaz.pdf. Acesso em: 6 ago. 2017.

PANOFSKY, Erwin. O significado nas artes visuais. Lisboa: Ed. Presença, 1989.

SMUDJA, Ivana, SMUDJA, Gradimir. AuFil de l'Art, volume 1. Paris: Delcourt, 2012.

SOUSA, Mauricio de. História em Quadrões - Pinturas de Mauricio de Sousa. São Paulo: Ed. Globo, 2001.

História em Quadrões com a Turma da Mônica, 2. São Paulo: Ed. Globo, 2010.

ZÖLLNER, Frank. Leonardo. Lisboa: Taschen, 2006. 